\title{
An Observational Study of Paediatric Preoperative Transfusion Practice in a Resource-Limited Setting
}

\author{
Somy Charuvila ${ }^{1}$ Tasmiah Tahera Aziz $^{2} \cdot$ Sarah E. Davidson $^{1} \cdot$ Ummay Naznin $^{2} \cdot$ Shiuly Sinha $^{2}$. \\ Sabbir Ahmed ${ }^{2} \cdot$ Kokila Lakhoo $^{1} \cdot$ Tahmina Banu $^{2}$
}

\begin{abstract}
Background Paediatric anaemia is highly prevalent in low-middle-income countries and can negatively impact postoperative outcomes. Currently, there are no guidelines for the management of paediatric preoperative anaemia. To ensure optimal care in resource-limited settings: balancing the risks of anaemia and using resources such as blood transfusion, we first need to understand current practices. To address this, a joint UK-Bangladesh team conducted an observational study at a paediatric surgical centre in Bangladesh.

Methods A total of 464 patients $\leq 16$ years who underwent elective and emergency surgery were categorised into major (351/464), moderate (92/464) and minor (21/464) surgery groups according to anticipated blood loss. Preoperative anaemia testing and transfusion was assessed retrospectively through patient notes.

Results Median age was 4 years and $73 \%$ were male. $32.5 \%$ (151/464) patients had preoperative blood testing for anaemia. $17.5 \%$ (81/464) children were transfused preoperatively. Of those children transfused, $40.7 \%(33 / 81)$ underwent transfusion solely based on visible signs of anaemia on clinical examination. Seventy-five percentage (36/ 48) of children who underwent transfusion after blood testing had haemoglobin $\geq 80 \mathrm{~g} / \mathrm{L}$. Major surgery category had the highest proportion of children who were transfused and tested for anaemia.

Conclusion A liberal transfusion approach is evident here. Discussion with local clinicians revealed that this was due to limitations in obtaining timely blood results and reduction in laboratory costs incurred by families when clinical suspicion of anaemia was high. Further research is needed to analyse the potential of using bedside haemoglobin testers in conjunction with patient blood management strategies to limit blood transfusions and its associated risks.
\end{abstract}

Kokila Lakhoo and Tahmina Banu: Joint principal investigators/ senior authors.

\section{Somy Charuvila}

somysamuel@gmail.com

1 Oxford University Global Surgery Group, Nuffield Department of Surgical Sciences, University of Oxford, Oxford, UK

2 Chittagong Research Institute for Children Surgery (CRICS), Chittagong, Bangladesh

\section{Introduction}

Paediatric anaemia is a major public health issue in developing countries owing to factors such as nutrition, infections and socioeconomic status. Anaemia is associated with higher mortality and organ dysfunction post-surgery [1]. It can increase length of hospital stay, blood transfusions and intensive care requirements [2].

Preoperative anaemia testing and treatment through patient blood management strategies, including restrictive transfusion, was discussed in our recent literature review [3]. To our knowledge, there is no guideline for paediatric 
preoperative anaemia testing and treatment in low-resource settings.

To address this, a global partnership between multidisciplinary professionals in the UK and Bangladesh was formed. To begin this process, an investigation of current practices was carried out at a major paediatric surgical centre in Bangladesh. This was done retrospectively from patient records and is described in this paper.

Prevalence of paediatric anaemia in Bangladesh has been quoted to be as high as 52\% [4] and up to 24\% [5] of children under 5 years in one study were identified to have severe anaemia [6]. Bangladesh's economic status and high anaemia prevalence make it a suitable healthcare system for this study.

Health care in Bangladesh can be obtained from government and private sectors. At government institutions, patients do not incur consultation or operation fees. Their expenditure mainly involves investigations, medical supplies, food, accommodation and transport. Worldwide, 81 million people are estimated to experience financial catastrophe as a result of a surgical condition [7]. Health expenditure is significant, considering that $31.5 \%$ of the population in Bangladesh live below the poverty line and $70 \%$ live in areas with limited health care [8].

Chittagong Medical College Hospital (CMCH) in Bangladesh was chosen for this study as it is a government hospital with a paediatric surgery department serving a population of 30 million. It has a caseload of 2100 operations per year ranging from day cases to major surgeries. The centre has a long-standing partnership with a centre in the UK. It also has an outreach service facilitating surgical care for children in rural areas [9].

In the Chittagong region, anaemia prevalence in the 6to 59-month age category has shown to be greater than $50 \%$ [10]. Despite the high prevalence, preoperative anaemia testing is not routine due to financial and infrastructural barriers. Table 1 indicates costs associated with blood tests and transfusion. Transfusion services such as screening, cross-matching and blood grouping are available all day. However, standard blood tests such as full blood count are done only from 8 am to $4 \mathrm{pm}$. Out-of-hours investigations can be obtained at higher costs from private centres. A recent study on COVID-19's impact on economic loss in Bangladesh estimates that nearly $35 \%$ of workforce are daily wage earners receiving 272.2 Bangladeshi Taka (BDT) per day in the farm sector and 361.5 BDT per day in other sectors [11]. This estimation uses data from the most recent Household Income Expenditure Survey in Bangladesh (HIES) 2016-2017 conducted by the Bangladesh Bureau of Statistics. These figures may be subject to inflation and changes in living costs, and Table 1 nevertheless reflects the high cost of basic diagnostic services when compared to average daily wages.

Currently, there are no established criteria at $\mathrm{CMCH}$ to guide preoperative transfusion. When financial or logistical challenges limit preoperative anaemia testing, clinicians at $\mathrm{CMCH}$ use general medical knowledge of signs and symptoms of anaemia to clinically diagnose anaemia. Due to the high prevalence of untreated anaemia, clinicians often see signs of anaemia on examination. Conjunctival pallor, koilonychia, brittle nails, angular stomatitis, tachycardia in elective consultation and malnourished appearance are used to clinically diagnose anaemia. Symptoms such as fatigue, history of chronic illness or previous deworming treatment are also taken into consideration.

Most government diagnostic facilities are open only from 8 am to $4 \mathrm{pm}$. The high caseload and limited staff undertaking phlebotomy, transporting samples, preparation of laboratory equipment and the wait for an available automated analyser impact the productivity output from the

Table 1 Cost comparison of blood diagnostic services at $\mathrm{CMCH}$ (government establishment) and at private centres in Bangladesh. Rates are Bangladeshi Taka (BDT). The average daily wage worker earns 272.2. BDT in the farm sector and 361.5 BDT in the non-farm sector

\begin{tabular}{lll}
\hline Investigation & $\begin{array}{l}\text { CMCH (government hospital) costs in } \\
\text { Bangladeshi Taka (BDT) }\end{array}$ & $\begin{array}{l}\text { Cost range for private diagnostic centres } \\
\text { in Bangladeshi Taka (BDT) }\end{array}$ \\
\hline $\begin{array}{l}\text { Full blood count (haemoglobin, total count, differential } \\
\quad \text { count and erythrocyte sedimentation rate) }\end{array}$ & 150 & $(300-400)$ \\
$\begin{array}{l}\text { Haematocrit alone } \\
\text { Routine preoperative screening blood test set (admitted } \\
\quad \text { patient) }\end{array}$ & 30 & $(150-200)$ \\
$\begin{array}{l}\text { Routine preoperative screening blood test set (non- } \\
\text { admitted patient) }\end{array}$ & 500 & $(900-1200)$ \\
$\begin{array}{l}\text { Blood grouping and rhesus typing } \\
\text { Cross-matching }\end{array}$ & 100 & $(900-1200)$ \\
Single transfusion set & 100 & $(300-400)$ \\
\hline
\end{tabular}


laboratory between the constricted hours of 8 am to $4 \mathrm{pm}$. Moreover, results are not relayed after $4 \mathrm{pm}$ due to lack of trained staff. Hence, it takes up to $24 \mathrm{~h}$ to obtain blood results in government hospitals like $\mathrm{CMCH}$.

In cases where financial and logistical implications pose a challenge to anaemia testing, the anaesthetist and in some cases the senior surgical consultant initiate transfusion based on their clinical judgment. For those patients who undergo preoperative anaemia testing, clinicians use the maximum allowable blood loss calculation to guide transfusion [12]. between 2014 and 2016 were included in this study. Data were retrospectively collected using a standardised proforma which included patient demographics, investigations, operative procedure, type of anaesthetic and details on preoperative anaemia testing and transfusion. This study did not impact clinical care of any patients and was strictly a retrospective observational study.

Data were collected by two research assistants at $\mathrm{CMCH}$ from October 2019 to December 2019. Video conferences were held between clinicians from the Bangladesh and UK teams throughout the study. Anonymised patient data from proformas were transferred to an excel spreadsheet which

Maximum allowable blood loss

$$
=\text { Estimated blood volume } \frac{\text { (Child's haematocrit }- \text { Minimum accepted haematocrit: i.e. } 20 \% \text { in children })}{\text { Child's Haematocrit }}
$$

If there is significant risk of blood loss $(>7 \mathrm{mls} / \mathrm{kg})$ as per the WHO Safe Surgery checklist, transfusion is requested even when there is low clinical suspicion or laboratory confirmation of anaemia. Other factors such as active bleeding, prolonged surgery, emergency surgery and coexisting malnourishment or haemoglobinopathy are also used to guide transfusion. Generally, a transfusion dose of $20 \mathrm{~mL} / \mathrm{kg}$ of body weight is used.

Transfusion is also offered in non-urgent cases at $\mathrm{CMCH}$. This is due to a backlog of elective surgeries and family resistance in postponing surgery for treatment of anaemia as they travel from rural areas and cannot afford further days off from work. Children are frequently brought to hospital when their chronic condition deteriorates and delaying their surgery can worsen outcomes.

To assess the current preoperative transfusion practice at $\mathrm{CMCH}$, we conducted a retrospective study. Our aim was to investigate the proportion of children undergoing preoperative testing and transfusion when categorised according to surgical complexity. We focus on transfusion as the modality of anaemia treatment as it poses a significant challenge in terms of safety, logistics and cost.

\section{Methods}

\section{Data collection}

A total of 464 children aged 16 years or under (excluding neonates) who underwent elective and emergency surgery was analysed by researchers in the UK team.

\section{Data analysis}

All patients were analysed according to major, moderate or minor surgery: this is an established criteria at $\mathrm{CMCH}$ and is used to clinically triage resources such as pre-op assessment, hospital beds and blood transfusion to patients. This categorisation is defined according to likelihood of performing the case under local or general anaesthesia and whether blood transfusion is likely based on the risk of blood loss.

For example, major surgery includes splenectomy, bowel surgery and solid organ tumour removal. These procedures are done under general anaesthetic and more likely to necessitate transfusion. Moderate surgery includes hernia repair and cystoscopic procedures. Examples of minor surgery include circumcision and keloid excision which are generally low risk, performed under local anaesthetic and are very unlikely to require transfusion.

Statistical significance between the number of patients tested for anaemia in each group was assessed using the Chi-squared $\left(\chi^{2}\right)$ test. Proportion of patients who underwent preoperative blood transfusion was also assessed in these groups.

For those patients who underwent preoperative anaemia testing, we categorised them into two groups:

Transfused versus non-transfused For those patients who underwent preoperative anaemia testing, we assessed the mean difference in preoperative haemoglobin values between those transfused and not. Statistical significance 
between the mean preoperative haemoglobin of these two groups of patients was analysed using the t-test.

\section{Results}

\section{Patient demographics}

Table 2 shows patient demographics.

Table 3 shows the range of surgical procedures included in this study.

\section{Preoperative transfusion practice}

Table 4 and Fig. 1 outline the transfusion practice by surgical category.

Overall, 81 of the total 464 children were transfused of whom $85 \%$ (69/81) were in the major surgery category. One patient in the minor surgery category with a recorded $\mathrm{Hb}$ of $120 \mathrm{~g} / \mathrm{L}$ underwent transfusion for faecaloma extraction. This outlier was due to anticipated blood loss

Table 2 Patient demographics

\begin{tabular}{|c|c|c|}
\hline & $n$ & $\%$ \\
\hline Total & 464 & \\
\hline \multicolumn{3}{|l|}{ Age } \\
\hline Median & 4.25 years & \\
\hline Range & 2 days to 16 years & \\
\hline Children $<1$ year & 90 & 19 \\
\hline Children $<1$ month & 13 & 2.8 \\
\hline \multicolumn{3}{|l|}{ Sex } \\
\hline Female & 121 & 26 \\
\hline Male & 341 & 73 \\
\hline Disorder of sex development & 2 & 0.4 \\
\hline \multicolumn{3}{|l|}{ Type of surgery } \\
\hline Major & 351 & 76 \\
\hline Moderate & 92 & 20 \\
\hline Minor & 21 & 4 \\
\hline \multicolumn{3}{|l|}{ Type of anaesthetic } \\
\hline General & 447 & 96.3 \\
\hline Spinal & 8 & 1.7 \\
\hline Sedation & 6 & 1.3 \\
\hline Local & 3 & 0.6 \\
\hline \multicolumn{3}{|l|}{ Transfusion status } \\
\hline Transfused & 81 & 17.5 \\
\hline Non-transfused & 383 & 82.5 \\
\hline \multicolumn{3}{|l|}{ Preoperative anaemia testing } \\
\hline Tested & 151 & 32.5 \\
\hline Non-tested & 313 & 67.5 \\
\hline
\end{tabular}

Table 3 Surgical procedures underwent by patients in this study

\begin{tabular}{ll}
\hline Surgical procedure & $N$ \\
\hline Laparotomy (trauma, obstruction, tumour, splenectomy) & 99 \\
Urethroplasty/hypospadias/chordee release & 67 \\
Cystoscopy_diagnostic and procedural & 47 \\
Cleft lip/cleft palate repair & 44 \\
Anoplasty/genitoplasty & 42 \\
Burn contracture release/graft & 24 \\
Teratoma/parotid/cystic hygroma/goitre removal & 24 \\
Haemangioma excision/sclerotherapy & 20 \\
Pull through procedure for Hirschsprung's & 20 \\
Hernia repair & 18 \\
Minor wound debridement/abscess/keloid or cyst removal & 13 \\
Nephrostomy & 6 \\
Anal fistula procedure & 5 \\
Pyloromyotomy & 5 \\
Circumcision & 4 \\
Cystostomy formation & 4 \\
Diagnostic laparoscopy & 4 \\
Urethral fistula repair & 4 \\
Endoscopy & 4 \\
EUA & 2 \\
Ureteric implantation & 3 \\
Foreign body chest wall & 3 \\
Syndactyly repair & 3 \\
Orchidopexy & 3 \\
& 4 \\
& 3
\end{tabular}

from the inflamed colonic wall. $40.7 \%$ (33/81) of patients underwent transfusion without prior blood test confirming anaemia.

Only 151 out of the total 464 patients had preoperative anaemia testing. Among these 151 children, we compared the haemoglobin values of patients who were transfused vs non-transfused. This is displayed in the box and whisker plot chart in Fig. 2.

The mean preoperative haemoglobin of $94.9 \mathrm{~g} / \mathrm{L}$ in the transfused group is lower than that of the non-transfused group $103.7 \mathrm{~g} / \mathrm{L}$. This difference is statistically significant ( $p=0.003)$ as per the t-test.

Patients who were transfused had lower haemoglobin values. However, the haemoglobin threshold which guided the decision to transfuse is not evident. Clinical context was used to determine the need for transfusion. Indeed, patients above the World Health Organization anaemia threshold ranges were also transfused [13] (Fig. 2). Among the 48 patients transfused after a blood test, $75 \%(36 / 48)$ had an $\mathrm{Hb} \geq 80 \mathrm{~g} / \mathrm{L}$ as indicated by their lower quartile mark in Fig. 2. 
Table 4 Data on the transfusion practice according to the type of surgery

\begin{tabular}{lccc}
\hline & Major & Moderate & Minor \\
\hline Total patients $(n=464)$ & 351 & 92 & 21 \\
Total transfused $(n=81)$ & 69 & 11 & 1 \\
Transfused after haemoglobin testing $(n=48)$ & 44 & 3 & 1 \\
Transfused without haemoglobin testing $(n=33)$ & 25 & 8 & 0 \\
\hline
\end{tabular}

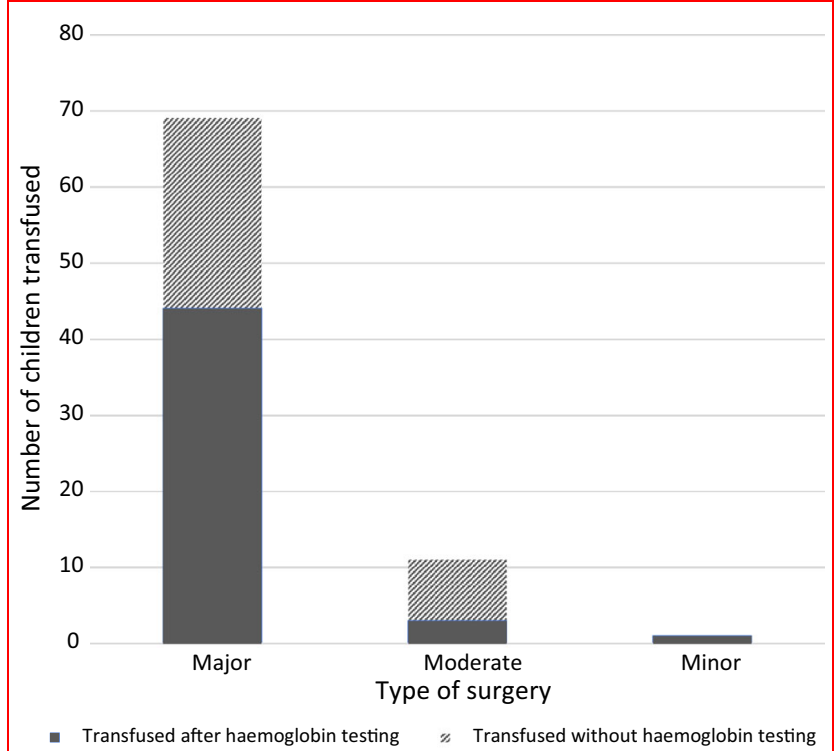

Fig. 1 Comparison of the transfusion practice according to the type of surgery

\section{Preoperative anaemia testing practice}

Majority of patients tested for anaemia fell into the major category (Table 5). $X^{2}$ test indicates the testing rates among the different groups are statistically significant $\left(p=3.2637 \times 10^{-5}\right)$.

Of the 464 patients in this retrospective analysis, there was $0 \%$ mortality at 6 months postoperatively.

\section{Discussion}

This study has highlighted disparities in care owing to financial, infrastructural and cultural reasons. This study had a significantly high percentage of males (73\%). Studies in Bangladesh and south Asia have shown that the sex of a child can influence parental health seeking behaviour and adherence to treatment [14-16]. However, these factors were not investigated in this study and hence we cannot determine the reasons for this difference.
Majority of children (76\%) underwent major surgery. $\mathrm{CMCH}$ being a large tertiary centre receives many complex referrals from less equipped hospitals. The high percentage of major surgery also potentially reflects the culture in rural communities where parents do not seek surgical intervention until significant deterioration of their child's condition.

Here, $85 \%$ of those transfused underwent major surgery which is usually associated with higher risk of blood loss and coexisting medical comorbidities. Forty percentage of patients transfused had not undergone prior blood testing for anaemia, again with a predominance in the major surgery group. In patients with visible features of anaemia undergoing emergency surgery with high risk of blood loss, clinicians did not request preoperative anaemia testing due to the long waiting time for blood results (up to $24 \mathrm{~h}$ ). Clinicians were also significantly influenced by families' ability to cover testing costs.

Seventy-five percentage of the patients who underwent haemoglobin testing prior to transfusion had a haemoglobin $>80 \mathrm{~g} / \mathrm{L}$. Discussion with clinicians outlines reasons such as anticipated volume of blood loss and comorbidities of the patient. Similarly, a Chinese study of 1506 children undergoing intraoperative transfusion found that $45.3 \%$ of those transfused had an $\mathrm{Hb}>80 \mathrm{~g} / \mathrm{L}$ and $28.8 \%$ had $\mathrm{Hb}>100 \mathrm{~g} / \mathrm{L}$. This was attributed to haemodynamic parameters, body size, clinician preference and lack of paediatric perioperative guidelines [17].

Although preoperative anaemia carries negative outcomes, the haemoglobin threshold to warrant postponement of surgery is unknown. Evidence from the landmark Canadian paediatric ICU trial involving 637 children showed that in stable critically ill children, a threshold of $70 \mathrm{~g} / \mathrm{L}$ can reduce the transfusion requirements without being associated with adverse outcomes when compared to a liberal threshold of $95 \mathrm{~g} / \mathrm{L}$ [18]. A Danish study of 210 adolescents undergoing scoliosis surgery also advocated a threshold of $70 \mathrm{~g} / \mathrm{L}$ [19].

A review of six studies also concluded that a threshold of $69.3 \mathrm{~g} / \mathrm{L}$ for children admitted to ICU with burns, sepsis or after general and cardiac surgery was safe (excluding cyanotic heart disease) [20]. Importantly, these studies on restrictive transfusion were conducted in settings well resourced for monitoring and testing. Additionally, they 
Fig. 2 Preoperative haemoglobin values in transfused versus nontransfused groups where $n$ indicates the number of patients in each group who have recorded haemoglobin values

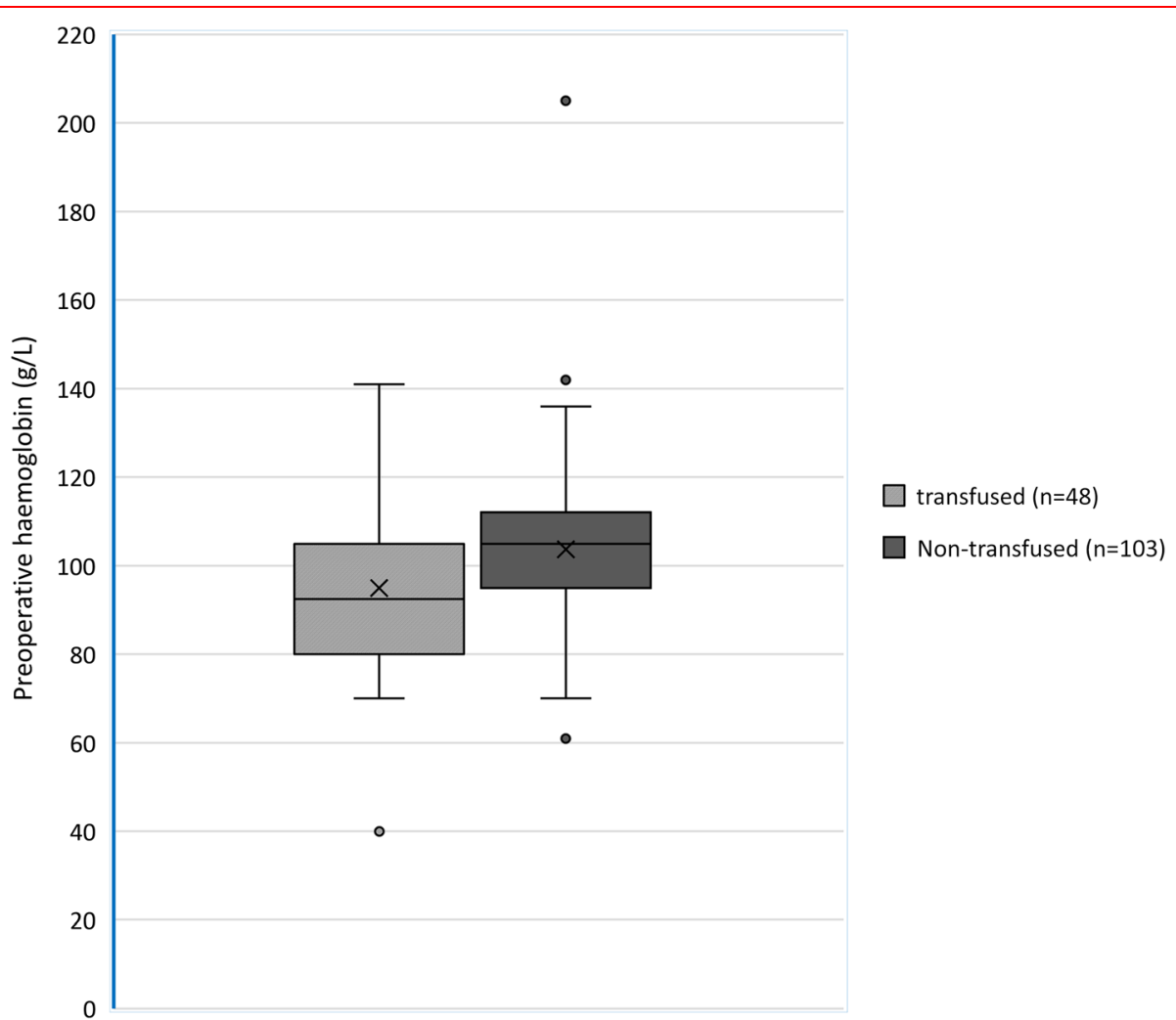

Table 5 Testing rates according to category of surgery

\begin{tabular}{lcc}
\hline & Haemoglobin tested $(n=151)$ & Haemoglobin non-tested $(n=313)$ \\
\hline Major $(n=351)$ & 133 & 218 \\
Moderate $(n=92)$ & 12 & 80 \\
\hline
\end{tabular}

have been done in the context of the critical care and cannot be translated directly to the preoperative setting.

The likelihood of over-transfusion in this study is high because clinical assessment of anaemia can be subjective. Blood transfusion carries several risks including infections, febrile reactions, donor mismatch, lung injury and anaphylaxis. Clinicians at $\mathrm{CMCH}$ reported febrile reactions, urticarial, allergic reactions and fluid overload in the last 5 years.

Screening donated blood for HIV, HBV, HCV, syphilis and malaria is mandatory in Bangladesh. However, studies in Bangladesh and India have shown the presence of hepatitis $\mathrm{B}$ in donated blood that underwent pre-transfusion screening [21-23]. This is potentially due to lack of trained staff and highly sensitive modalities of screening.

Transfusion also poses logistical challenges. Due to the high prevalence of blood borne infections among paid donors, the Safe Blood Transfusion initiative was implemented in Bangladesh, which led to a sharp decrease in the number of paid donors from 70 to $10 \%$ in the early 2000s [24]. Hence, blood banks depend on blood donation from relatives, voluntary organisations and hospital staff (when there is a lack of donors and families are unfit to donate).

Blood for donation is usually arranged on demand. For non-urgent cases at $\mathrm{CMCH}$, it can take up to $18 \mathrm{~h}$ to carry out donor selection, screening, cross-matching and organising equipment. Written informed consent is taken prior to transfusion.

The health risks and costs highlight the need for titration of transfusion to haemoglobin levels. Bedside point-of-care (POC) haemoglobin testing can increase preoperative anaemia testing. POC testing for perinatal HIV, syphilis and malaria infections have been shown to be very useful in resource-limited settings [25]. POC anaemia testing has been demonstrated to be of comparable accuracy to 
Fig. 3 Proposed new guideline for future prospective study. This guideline was created in response to the findings of this retrospective study
Proposed new guideline for preoperative anaemia management

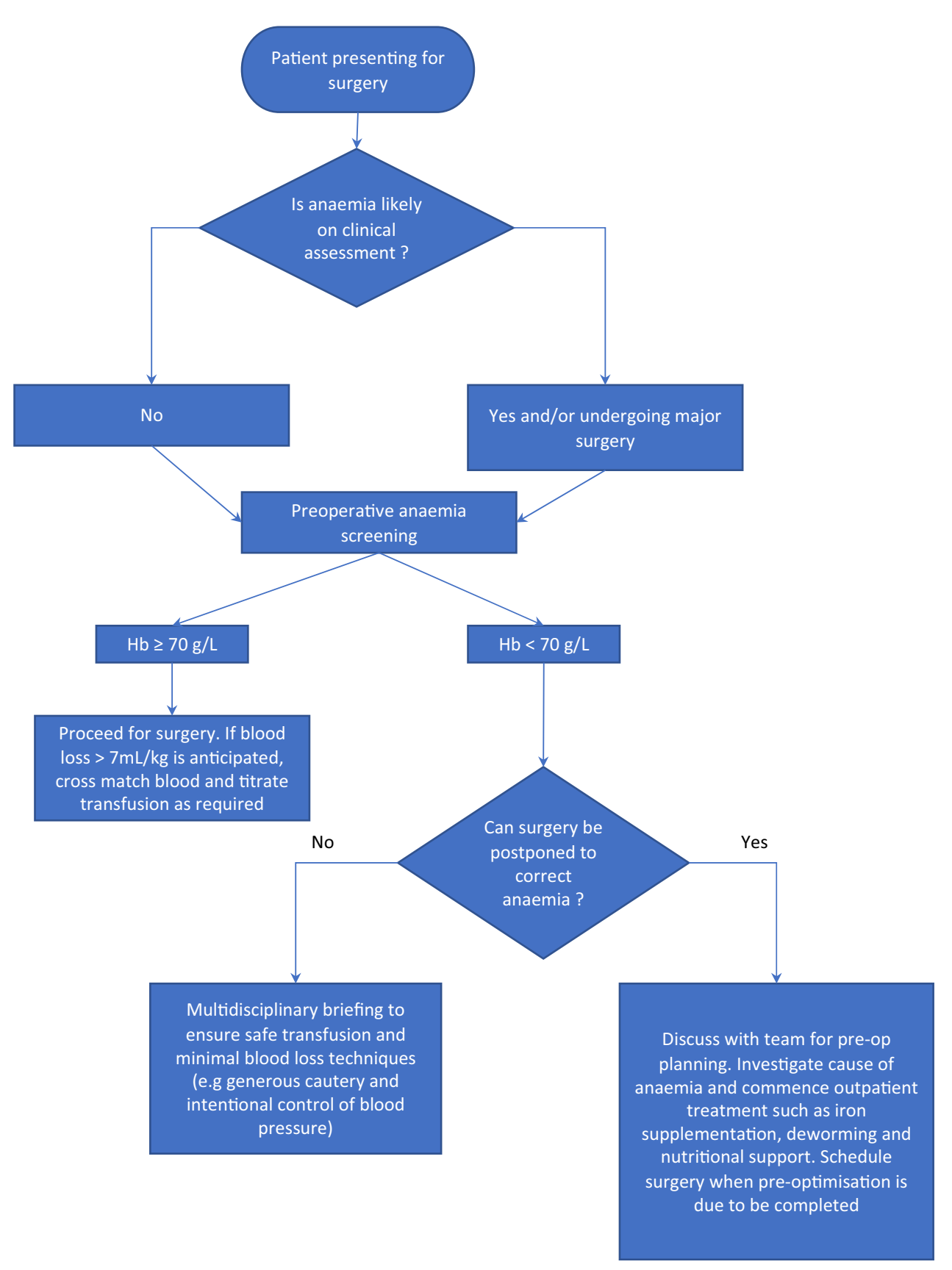

standard methods [26]. A meta-analysis showed that diagnosing anaemia via POC testing was more accurate than clinical assessment alone [27].

We propose a prospective study on the clinical impact of POC anaemia testing alongside a restrictive transfusion approach. To conduct the prospective study, we have created a new decision-making guide (Fig. 3). This guide involves a multidisciplinary decision-making approach in aspects such as restrictive blood transfusion, intentional blood pressure control, generous cautery, judicious use of tourniquets and tranexamic acid to reduce bleeding on a case-by-case basis.

Tranexamic acid is a widely available drug at $\mathrm{CMCH}$ and is currently considered on an individual basis in the context of trauma and surgery involving significant risk of blood loss $(>7 \mathrm{mls} / \mathrm{kg})$. Tranexamic acid has been recommended in paediatric trauma and major surgery as there 
is evidence that it reduces perioperative blood loss and need for transfusions [28].

This new proposed guide suggests postponing elective surgery in certain cases, after careful consideration of the patient's clinical picture and financial circumstances (such as travel and accommodation costs for patients from rural regions). Where postponing surgery will not impact long term health, expedited surgery can be arranged after optimisation of haemoglobin level.

As part of this prospective study, educational awareness regarding transfusion risks and patient blood management strategies is being given to clinicians at $\mathrm{CMCH}$ and rural referring hospitals through existing outreach programs.

\section{Conclusion}

This study has highlighted the complexity of the decisionmaking process in preoperative anaemia assessment and management in a resource-limited setting. Discussions with local clinicians have given insight into the challenges presented by lack of affordable rapid anaemia testing.

Restrictive transfusion in conjunction with increased preoperative anaemia testing may be beneficial in resourcelimited settings. We aim to analyse this in a prospective study.

Acknowledgements The authors would like to thank the Children's Research Fund. The authors also would like to thank Sakibul Alam, Chittagong Research Institute for Children Surgery (CRICS), who helped to facilitate data collection.

Funding The study was funded by the Children's Research Fund.

\section{Declaration}

Conflict of interests The authors declare that they have no competing interests.

Open Access This article is licensed under a Creative Commons Attribution 4.0 International License, which permits use, sharing, adaptation, distribution and reproduction in any medium or format, as long as you give appropriate credit to the original author(s) and the source, provide a link to the Creative Commons licence, and indicate if changes were made. The images or other third party material in this article are included in the article's Creative Commons licence, unless indicated otherwise in a credit line to the material. If material is not included in the article's Creative Commons licence and your intended use is not permitted by statutory regulation or exceeds the permitted use, you will need to obtain permission directly from the copyright holder. To view a copy of this licence, visit http://creativecommons. org/licenses/by/4.0/.

\section{References}

1. Faraoni D, DiNardo JA, Goobie SM (2016) Relationship between preoperative anemia and in-hospital mortality in children undergoing noncardiac surgery. Anesth Analg 123:1582-1587

2. Fontanals M, O'Leary JD, Zaarour C, Skelton T, Faraoni D (2019) Preoperative anemia increases the risk of red blood cell transfusion and prolonged hospital length of stay in children undergoing spine arthrodesis surgery. Transfusion 59:492-499

3. Charuvila S, Davidson SE, Thachil J, Lakhoo K (2019) Surgical decision making around paediatric preoperative anaemia in lowincome and middle-income countries. Lancet Child Adolesc Health 3:814-821

4. Yusuf A, Mamun ASMA, Kamruzzaman M, Saw A, Abo ElFetoh NM, Lestrel PE, Hossain MG (2019) Factors influencing childhood anaemia in Bangladesh: a two level logistic regression analysis. BMC Pediatr 19:213

5. Afroja S, Kabir MR, Islam MA (2019) Analysis of determinants of severity levels of childhood anemia in Bangladesh using a proportional odds model. Clin Epidemiol Glob Health 8:175-180

6. Islam GMR (2019) Association of socioeconomic status with childhood anemia among infant, toddler, and preschool children in Bangladesh. Value Health Reg Issues 21:141-148

7. Shrime MG, Dare AJ, Alkire BC, O'Neill K, Meara JG (2015) Catastrophic expenditure to pay for surgery worldwide: a modelling study. Lancet Glob Health 3:S38-S44

8. Banu T, Chowdhury TK, Aziz TT, Das A, Tamanna N, Pulock OS, Imam MS, Karim A, Akter M, Walid A (2018) Cost incurred by the family for surgery in their children: a Bangladesh perspective. World J Surg 42:3841-3848. https://doi.org/10.1007/ s00268-018-4700-0

9. Banu T, Chowdhury TK, Kabir M, Talukder R, Lakhoo K (2013) Bringing surgery to rural children: Chittagong, Bangladesh experience. World J Surg 37:730-736. https://doi.org/10.1007/ s00268-013-1916-x

10. Khan JR, Awan N, Misu F (2016) Determinants of anemia among 6-59 months aged children in Bangladesh: evidence from nationally representative data. BMC Pediatr 16:3

11. Mottaleb KA, Mainuddin M, Sonobe T (2020) COVID-19 induced economic loss and ensuring food security for vulnerable groups: policy implications from Bangladesh. PLoS One 15:e0240709

12. Bharadwaj A, Khandelwal M, Bhargava SK (2014) Perioperative neonatal and paediatric blood transfusion. Indian $\mathrm{J}$ Anaesth 58:652-657

13. Organization WH, Others (2011) Haemoglobin concentrations for the diagnosis of anaemia and assessment of severity

14. Uddin MF, Molyneux S, Muraya K et al (2021) Gender-related influences on adherence to advice and treatment-seeking guidance for infants and young children post-hospital discharge in Bangladesh. Int J Equity Health 20:64

15. Mahmud I, Das S, Khan SH, Faruque ASG, Ahmed T (2020) Gender disparity in care-seeking behaviours and treatment outcomes for dehydrating diarrhoea among under-5 children admitted to a diarrhoeal disease hospital in Bangladesh: an analysis of hospital-based surveillance data. BMJ Open 10:e 038730

16. Ismail SA, McCullough A, Guo S, Sharkey A, Harma S, Rutter P (2019) Gender-related differences in care-seeking behaviour for newborns: a systematic review of the evidence in South Asia. BMJ Glob Health 4:e001309

17. Zhou H, Lan J, Zhu H, Tan X, Liu J, Xiang L, Guo C (2020) Evaluation for perioperative blood transfusion during major abdominal procedures in a pediatric population: a retrospective observation cohort study. Transfus Med Hemother 47:68-74 
18. Lacroix J, Hébert PC, Hutchison JS et al (2007) Transfusion strategies for patients in pediatric intensive care units. $\mathrm{N}$ Engl $\mathrm{J}$ Med 356:1609-1619

19. Ohrt-Nissen S, Bukhari N, Dragsted C, Gehrchen M, Johansson PI, Dirks J, Stensballe J, Dahl B (2017) Blood transfusion in the surgical treatment of adolescent idiopathic scoliosis-a singlecenter experience of patient blood management in 210 cases: blood management in idiopathic scoliosis. Transfusion 57:1808-1817

20. de Vetten L, Kneyber MCJ, Tamminga RYJ (2013) A restrictive transfusion policy in the paediatric intensive care unit: safe and effective. https://www.njcc.nl/sites/nvic.nl/files/pdf/review2.pdf. Accessed 26 Feb 2021

21. Jahan M, Islam MA, Akbar SMF, Takahashi K, Tabassum S, Rahman A, Haque MA, Biswas J, Mishiro S, Al-Mahtab M (2016) Anti-HBc screening of blood donors in Bangladesh: relevance to containment of HBV propagation. J Clin Exp Hepatol 6:115-118

22. Bhattacharya P, Chandra P-K, Datta S, Banerjee A, Chakraborty S, Rajendran K, Basu S-K, Bhattacharya S-K, Chakravarty R (2007) Significant increase in HBV, HCV, HIV and syphilis infections among blood donors in West Bengal, Eastern India 2004-2005: exploratory screening reveals high frequency of occult HBV infection. World J Gastroenterol 13:3730-3733

23. Asim M, Ali R, Khan LA, Husain SA, Singla R, Kar P (2010) Significance of anti-HBc screening of blood donors and its association with occult hepatitis B virus infection: implications for blood transfusion. Indian J Med Res 132:312-317

24. Islam MB (2009) Blood transfusion services in Bangladesh. Asian J Transfus Sci 3:108-110

25. Katoba J, Kuupiel D, Mashamba-Thompson TP (2019) Toward improving accessibility of point-of-care diagnostic services for maternal and child health in low- and middle-income countries. Point Care J Near-Patient Test Technol 18:17-25

26. Oladele O, Olatunde O, Abiola O, Oyinkansola A, Evelyn O, Babajide A, Kehinde O, Oyeku O (2016) Point-of-care testing for anaemia in children using portable haematocrit meter: a pilot study from Southwest Nigeria and implications for developing countries. Ethiop J Health Sci 26:251-258

27. Marn H, Critchley JA (2016) Accuracy of the WHO Haemoglobin Colour Scale for the diagnosis of anaemia in primary health care settings in low-income countries: a systematic review and meta-analysis. Lancet Glob Health 4:e251-e265

28. Goobie SM, Faraoni D (2019) Tranexamic acid and perioperative bleeding in children: what do we still need to know? Curr Opin Anaesthesiol 32:343-352

Publisher's Note Springer Nature remains neutral with regard to jurisdictional claims in published maps and institutional affiliations. 